\title{
The interplay between vegetation and water in mangroves: new perspectives for mangrove stand modelling and ecological research
}

\author{
Ronny Peters (D) Marc Walther $(\mathbb{D} \cdot$ Catherine Lovelock (D) - Jiang Jiang (iD) \\ Uta Berger (i)
}

Received: 23 August 2019/Accepted: 4 June 2020/Published online: 12 June 2020

(C) The Author(s) 2020

\begin{abstract}
It is commonly accepted that vegetation patterns and water supply mutually define each other. In mangroves, soil water salinity and the corresponding osmotic potential are the main drivers of plant water supply. Below-ground processes thus may be key for the structure and dynamics of mangrove stands. Nevertheless, existing simulation models describing mangrove forest dynamics do not quantify the water uptake of the single plant from the soil and traditionally neglect any feedback of the vegetation on the water availability, but instead use empirical, statistical models for plant competition affecting growth. We provide a brief review on the state of the
\end{abstract}

R. Peters $(\bowtie) \cdot$ U. Berger

Department of Forest Sciences, TU Dresden, Tharandt, Germany

e-mail: ronny.peters@tu-dresden.de

M. Walther

Department of Hydro Sciences, TU Dresden, Dresden, Germany

M. Walther

Helmholtz Centre for Environmental Research, UFZ

Leipzig, Leipzig, Germany

C. Lovelock

School of Biological Sciences, University of Queensland, Brisbane, Australia

J. Jiang

Department of Soil and Water Conservation, Nanjing

Forestry University, Nanjing, China art of mangrove forest models with an emphasis on how below-ground processes are regarded. We follow mainly two directions: (1) phenomenological concepts for competition for below-ground resources and (2) assessing the impact of salinity and water supply on the vegetation and possible feedback mechanisms from the vegetation to the below-ground conditions. We hypothesise that a coupled vegetation-groundwater model would avail us to better understand the dynamics and properties of mangrove systems, their capability to persist or rehabilitate under stressful hydrological conditions, as well as their response to environmental changes related to the groundwater system and transport. The benefits of such a joint approach would (i) constitute an intrinsic belowground competition description close to the governing processes and (ii) concurrently exploit secondary, constraining information from vegetation patterns to derive a new concept to acquire knowledge on subsurface heterogeneity and parametrisation. The aim of this paper is to lay the theoretical groundwork and guidelines for future modellers to follow in the creation of a more realistic mangrove model coupling above- and below-ground processes. The proposed modelling approach has the potential to be useful for a broad audience based particularly in forest sciences and plant ecology in general, but also for hydrodynamic modelling (e.g. subsurface flow and transport detected by vegetation patterns as above-ground proxy). 
Keywords Mangroves - Individual-based modelling · Below-ground competition · Model coupling $\cdot$ Groundwater modelling $\cdot$ Salinity

\section{Introduction}

Mangroves in changing environments

Mangroves are salt tolerant trees that form extensive ecosystems in low wave energy coastal settings of the tropics and subtropics. They provide important ecosystem services to the coastal zone, including supporting biodiversity and fisheries, and extraction of wood and timber for a range of uses, as well as providing vital coastal protection and flood control. Despite this importance, mangrove have been removed and degraded over their range, with only $50-70 \%$ of their original distribution remaining. Recovering their distribution has become a goal for conservation organisations, governments and communities in order to support sustainable coasts into the future. Mangrove tree tolerance of saline water is associated with high water use efficiency for primary production compared to other woody vegetation (Lovelock et al. 2017) and thus they can achieve high levels of productivity under conditions of low freshwater availability. This has led to their use as forest resources, sometimes associated with extensive plantings, in regions with low freshwater supply (e.g. middle-eastern nations, Bhat et al. 2004). There are many factors that will influence the types of mangroves (e.g. species composition, forest structure and productivity) that are rehabilitated or can establish in plantations. Models can help identify and understand the processes influencing rehabilitation and the potential outcomes.

Salinity of the soil water is a key factor influencing species composition and productivity of mangroves (Ball 1988a) and therefore influences mangrove stand development. Despite this ability to grow in saline water, their productivity is enhanced at salinities less than that of seawater, with species differing in their tolerance of saline water (Ball 1988b). Therefore, changes in the salinity of coastal environments, due to variation in precipitation, river flows and evaporative demand, or due to water use by competing plants, are likely to have large effects on both growth and species composition.

In some regions, climate change is leading to reduced precipitation and extreme precipitation events, which also influences freshwater availability in the coastal zone. Also, anthropogenic activities in coastal areas changes freshwater availability, since the need to supply water for an increasing human population and associated agriculture has reduced river flows to the coasts as rivers have been diverted for storage of water upstream.

Although mangroves are vulnerable to sea level rise over some of their range (Lovelock et al. 2015), they are also predicted to expand their aerial cover with sea level rise where habitat is available (e.g. coastal plains, Runting et al. 2017; Swales et al. 2019). But mangrove growth, species composition, forest productivity and structure that will develop with mangrove expansion and restoration will depend on freshwater availability on coasts. Since sea level rise is associated with intrusion of salt water further inland and into coastal aquifers, it can result in additional pressures on freshwater availability affecting mangrove growth (Sternberg et al. 2007; Traill et al. 2011) and species composition (Ellison et al. 2000; Hazra et al. 2002; Polidoro et al. 2010).

\section{Zonation patterns}

Mangroves have high levels of small-scale spatial variations in soil water potential gradients, which can result in (or contribute to) "zonation" of mangrove stands (i.e. small-scale patterns of species composition, species dominance, stand structure and allometric manifestation of trees among others). Such zonation patterns (ZPs) are often reported to occur parallel to the coastline since gradients perpendicular to the coastline seem to reflect best the variation in tidal inundation and the associated physico-chemical factors such as soil salinity or soil $\mathrm{pH}$. In this sense, the term ZPs includes not only species zonation, but also zonation in forest structure (varying between large forests with and without understory to dwarf forests), and tree allometry, referring to the relationship between stem diameter, tree height and canopy. Changes in the ratio of above-ground: below-ground biomass have also been reported (Saintilan 1997). Mangrove zonation refers thus to both inter-specific as well as intra-specific stand properties varying along a 
coast as a result of different salinity-alteration processes, including salt water dilution due to freshwater recharge, increase of subsurface salinity from mangrove transpiration, and amelioration of salinity due to periodical flooding and tidal activity (Fig. 1, after Bathmann et al. 2020).

Although several early studies document ZPs perpendicular to the coastline, many discuss patterns which are more complex or even missing. The complex interactions of the driving factors have been identified as the main reason for the latter. They include geomorphology (Thom 1967; Semeniuk 1983), gradients of redox potential or porewater sulphides (Matthijs et al. 1999), propagule sorting (Rabinowitz 1978), seed predation (Smith 1987), competition (Rabinowitz 1978) and physiological responses to gradients that influence below-ground processes, including inundation (Watson 1928; Crase et al. 2013), redox potential or porewater sulphides (Matthijs et al. 1999), and salinity (Ball and Pidsley 1995; Duke et al. 1998; Ellison et al. 2000). Additionally, Feller et al. (2003) found-in a comparative field experiment-variation in nutrient limitation of trees under different salinity conditions and that in scrub trees enrichment with nitrogen, which increased productivity of the trees, led to a significant increase in soil porewater salinity, which influences water availability due to changes in osmotic potential. Also, the importance of below-ground processes for the understanding of mangrove zonation were discussed by McKee (1993) who observed physiological adaptation of seedlings to soil physico-chemical patterns and modification of these patterns by adult trees.

The prominent role of the below-ground processes in forming mangrove zonation mirrors in the extreme drought resistance of mangrove plants: osmotic potential of saline soil water may be equivalent to matric potentials in arid conditions in non-mangrove vegetation. For example, seawater-when it is the sole water source for near-coastal mangrove trees (e.g. Rhizophora mangle) - has an osmotic potential of approximately $-2.5 \mathrm{MPa}$ (Ball 1988a), whereas the permanent wilting point for non-halophyte vegetation is defined as a soil matric potential of only $-1.5 \mathrm{MPa}$. The spatio-temporal variability of soil- and groundwater salinity therefore represents an important factor governing patterns in mangrove species distribution and structure.

State of the art of mangrove stand models

Computer models simulating mangrove stands are usually individual-based and thus describe the establishment, growth, and mortality of individual trees depending on light availability, nutrient availability, pore water salinity, and competition among others. They have been extensively used to investigate forest dynamics, to explore forest integrity and functioning, or to forecast the future development of the coastal forests (see, e.g. Berger et al. 2008b and refs. within; Twilley et al. 1999; Grueters et al. 2014). Since emergent properties at plot, regional, and landscape

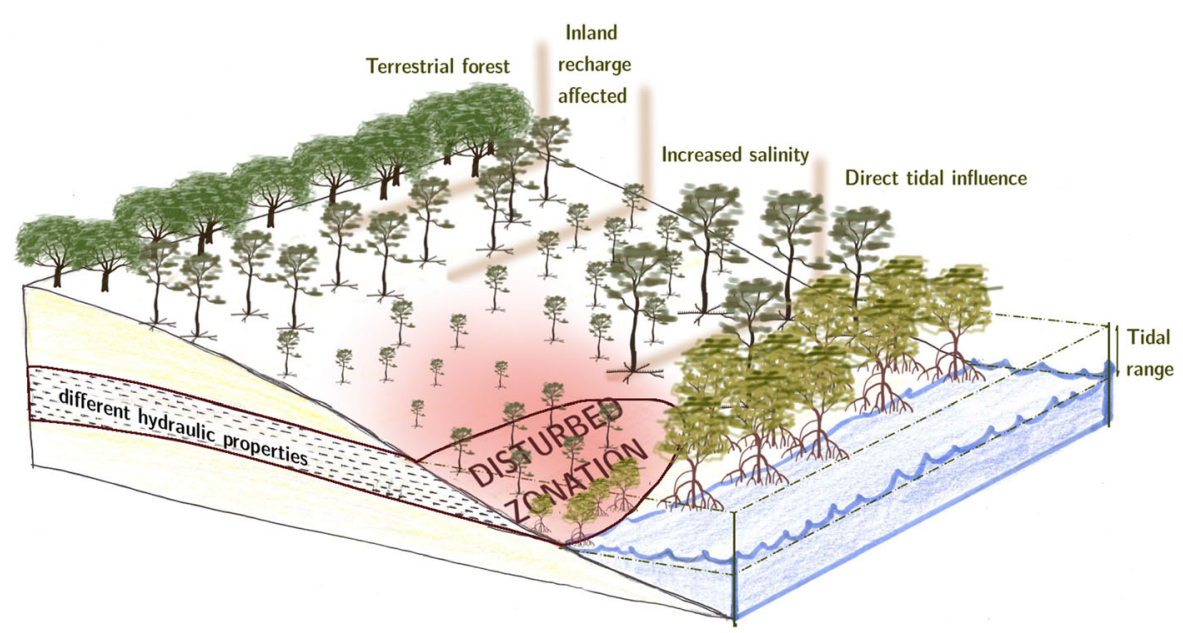

Fig. 1 Typical zonation in a mangrove system due to the hypothesised effect of the flooding gradient and disturbed zonation (red) modified by subsurface heterogeneity (after Bathmann et al. 2020) 
level evolve from the behaviour and interactions of the trees, simulation experiments support the explanation of spatial patterns and species composition (Berger et al. 2008c), give insight into succession stages after disturbances (Berger et al. 2006; Vogt et al. 2014; Teh et al. 2015; Jiang et al. 2016), or forecast the regeneration of degraded areas (Twilley et al. 1999; Berger et al. 2006) to name a few. Although the fundamentals of all individual-based forest models (IBM) are the same, namely the description of autonomous trees which vary in their characteristics and interact with their neighbours and environment, two types of mangrove forest IBM can be distinguished to date: (1) the pioneer group of IBM that is still established and considers the effect of soil salinity (and other abiotic factors such as nutrients and temperature) on tree growth phenomenologically namely as species-specific growth reducing factors (see, e.g. Chen and Twilley 1998; Doyle et al. 2003; Berger et al. 2008b; or Grueters et al. 2014), and (2) the group of more recent IBM that accounts for a mechanistic explanation of trees behaviour in the particular environmental setting. The latter describes explicitly the water uptake from the soil and the biomass allocation to the different parts of a tree (roots, stem, leaves etc., see Peters et al. 2014 or Jiang et al. 2016 for further details).

Beside all progress in the latter, urgently needed, mechanistic approach, its development is delayed by the insufficient theoretical framework for describing the relevant ecological processes, particularly the complex feedback mechanisms between hydrology and vegetation dynamics (Ellison 2000; Lewis et al. 2016). It should be noted that this accounts not only for mangrove forest models, but for forest models in general. Up to date, the most common concepts about tree competition focus on competition for light and use crown height, crown shape and tree size as main parameters to determine the competition strength a tree perceives in its local neighbourhood (Pretzsch 2010). Tietjen et al. (2009) provides one of the few approaches in terrestrial plant communities focussing on the interaction between vegetation and soil water dynamics. The currently available modelling approaches lack the integration of a comprehensive and mechanistic understanding of two-way interaction between the abiotic environmental conditions and forest dynamics. In almost all IBM, abiotic factors, like salinity or the availability of nutrients and water, are assumed constant in time and the mentioned competition concepts "bridge" the physical (and biological) subsurface processes just by shortening the access by "competitors". Horizontal and vertical redistribution and transport processes of water or nutrients influenced by trees physiology, as well as heterogeneous hydraulic soil properties or temporal and spatial gradients are not considered. This is particularly dramatic for the description of mangrove trees exposed to higher soil salinity because they have limited access and stronger impact to water and might thus require a greater focus in a realistic understanding of below-ground processes and the interaction to subsurface hydrology.

Here we develop a conceptual framework to link forest models with subsurface hydrological models. In particular, we focus on mangrove IBMs linked to variable-density flow and transport models in order to investigate and visualize the effect of varying freshwater availability on mangrove growth, and provide and stimulate the development of similar tools in other ecological fields. For this reason, we start with an overview about the state of the art of mangrove stand models (section "Present shortcomings and future challenges"). In section III, we present some shortcomings and limitations of current models. Section IV outlines a conceptual model that couples the subsurface water transport with tree growth and forest stand dynamics.

\section{Concepts of mangrove stand modelling}

Individual-based forest stand models require (i) the description of the single tree (allometry and growth) and (ii) the interaction among trees. We thus start with these sections before we present the overview about individual-based mangrove stand models. Please note that we focus primarily on processes related to tree growth and water dynamics, as processes like water uptake, distribution and availability form a decisive interface to subsurface processes and conditions. Other processes, like nutrient uptake, mortality and establishment are not explicitly addressed by the study presented. 
Descriptions of single tree allometry and growth

Descriptions of allometric relations in trees have been limited to empirically parametrised, mainly exponential relationships between allometric measures (e.g. Michailoff 1943; Shimano 1997; Chave et al. 2005; Komiyama et al. 2005, 2008) and are used in the majority of simulation models up to date. The advantage of such empirical approaches is that they can easily be adapted to stand data and experimentally gained data from specific locations under specific environmental conditions (Vovides et al. 2014). However, the development of a mechanistic explanation of the parameter values of these empirical relations has not been possible, which prevents the transfer or generalisation of those site- and speciescalibrated relationships, and the assessment of trees adaptation to environmental changes. The latter limits the assessment of climate change impacts on forests development, and is an issue beyond the narrow focus of mangrove models.

In all classic mangrove-IBMs (see Berger et al. 2008b for a comprehensive comparison of FORMAN, MANGRO and KiWi), the growth of the stem diameter (diameter at breast height, or $d b h$ ) under optimal conditions is described by the empirical formula introduced by the JABOWA model (Botkin et al. 1972) with $d b h$ converging asymptotically to a predefined species-specific maximum value. Additional plant measures (e.g. tree height or projected canopy area) are related to the stem diameter through other empirical relationships. Further, the dependence on water or nutrient availability and stress by increased salinity is represented by reduction factors. For example, the salinity multiplier function in the mangrove stand model FORMAN (Chen and Twilley 1998) and KiWi (Berger and Hildenbrandt 2000) with given salinity and species-specific parameters reduces the growth per time step, but does not affect maximum plant size nor reflect allometric adaptations to salinity.

To overcome the reliance on empirical equations bonded to particular environmental conditions, Peters et al. (2014) utilized osmotic potentials for incorporating the effect of water availability under salinity stress within the BETTINA model. This approach considers that allometric measures of a tree control the resource uptake and that the limitation of a specific resource promotes an increase in the corresponding part of the plant. For instance, if the plant is lacking water, an increase of the root zone diameter increases the fine root biomass and promotes water uptake. Further, girth growth increases $d b h$ and promotes water uptake even further via a bigger flow cross section. Similarly, light limitation fosters crown diameter growth. As such, the BETTINA model represents the first mechanistic single plant model describing allometric plasticity of mangrove trees in response to environmental conditions, i.e. water availability (directly linked to soil salinity) and light availability. The BETTINA model was, for example, used to simulate mangrove stands at the Braganca peninsula in Para, Brazil. Results are in agreement with field measures over a broad range of salinities (Olagoke 2016).

\section{Interaction concepts}

Tree-to-tree competition for resources, both aboveand below-ground, is key for plant growth and community dynamics (Grace 2012) since growth of individual trees is constrained by the most limiting resource and further reduced or improved by neighbourhood interactions (i.e. competition or facilitation). With this, the spatial constellation of trees has significant impact on the amount of the particular resource a single individual can access. As the properties of the system emerge from the characteristics, behaviour and interactions of the individual organisms (Breckling et al. 2005; Reuter et al. 2005), neighbourhood interactions and spatial constellations influence the size class structure, spatial patterns and tree density of a plot. Thus, an adequate description of plant interactions is essential for the modelling of plant populations and communities.

There are several phenomenological approaches to describe the effect of neighbourhood interaction (competition or facilitation as a positive effect) on tree growth (and subsequent mortality) through resource reduction (see Czárán 1998, for a still valid overview on such approaches).

Models with an explicit consideration of the distances between trees are grouped into Fixed Radius Neighbourhood models (FRN), Zone Of Influence models (ZOI) and Ecological Field models (EF). FRN models (Pacala and Silander 1985) are an early concept of competitive selection. A plant is regarded as a competitor if it is located within a fixed radius around the focal plant. A similar, yet more 
sophisticated, and widely accepted concept of describing plant interactions is the ZOI approach (Weiner et al. 2001). Plants are characterized by size-dependent (e.g. biomass-dependent), circular-shaped zones marking the space where the plant is able to obtain resources. In regions where ZOIs of different plants overlap, resources are shared depending on the comparative size of the tree and mode of interaction (Fig. 2). For instance, if plants compete for light, in the concept of asymmetric competition, the larger tree is assumed to have an advantage and secures a larger share of the resources from the disputed area. In contrast, equal resource sharing or resource sharing proportional to the size ratio (e.g., biomass ratio) of the involved plants (as assumed for below-ground processes, e.g. Schwinning and Weiner 1998; Berger et al. $2008 b$ ) is called symmetric competition.

A further advancement from the FRN and ZOI approaches is the EF theory (Wu et al. 1985). The EF is a concept that describes the strength of the impact of plants on a specific resource depending on the distance from the tree. The EF was considered radially symmetrical and from this concept Berger and Hildenbrandt (2000) developed the Field of neighbourhood (FON) approach to describe the interactions between neighbouring plants in the context of mangrove ecology (Fig. 3). The FON approach describes the strength of the influence of a tree on its neighbours depending on the distance from the tree.

\section{symmetric competition}

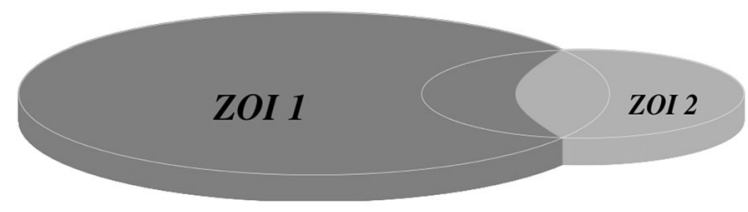

asymmetric competition

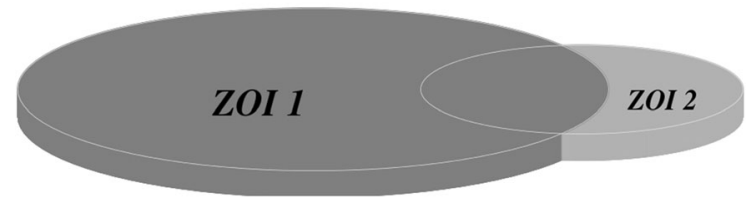

Fig. 2 Zone of influence (ZOI) concept: resource distribution for complete symmetric competition (top) and complete asymmetric competition (bottom) for two neighbouring plants
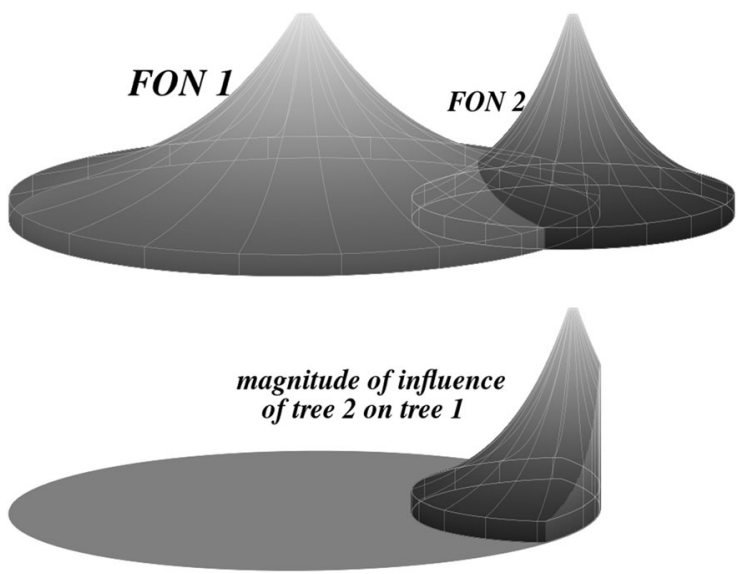

Fig. 3 Field of neighbourhood (FON) concept: intersecting FONs of two neighbouring plants (top); the influence of tree 2 on tree 1 is depending on the volume that the fraction of the FON 2 (from tree 2) covers within the radius of FON 1 (tree 1) in relation to the total circle area of FON 1 (bottom)

Models of mangrove forest dynamics

By combining multiple instances of single tree models (section II.1) with interaction concepts (section II.2), individual-based models can be created, which can be used to investigate the development of mangroves stands over time. The first individual-based mangrove stand model, FORMAN, was introduced by Chen and Twilley (1998). FORMAN was designed to simulate the development of mangrove stands consisting of the three main species of the western hemisphere Avicennia germinans, Rhizophora mangle and Laguncularia racemosa. The individuals were characterized by their stem diameter and a corresponding height (fixed allometric relationships). Competition and abiotic factors regulated growth rates until they reached an asymptotic maximum or these factors triggered the death of the tree. The FORMAN was a gap model, which assumes all the species in the gap influence each other, therefore, limiting the size of the gap for simulation.

The KiWi model (Berger and Hildenbrandt 2000; Berger et al. 2008a) was conceptually based on the FORMAN model in terms of individual tree growth processes, allometric relations (i.e. diameter-height relation), and the influence of salinity and nutrient availability on growth. The novelty, and an advantage, of the KiWi model was the approach to neighbourhood competition using the FON concept, which was spatially explicit and dependent on the size and the 
spatial position of the competitors. Based on the KiWi model, Grueters et al. (2014) designed the mangrove forest dynamics model mesoFON. In this model, growth functions and allometric relationships were similar to those in FORMAN and $\mathrm{KiWi}$, but each single tree was described by two FONs instead of one in order to describe above- and below-ground competition simultaneously. In addition, the mesoFON allows for the simulation of crown displacements as a strategy to avoid light competition by adequately changing the centre of gravity of the above-ground FON with respect to the position of the shaft during the growth process.

Based on the BETTINA single-tree model (Peters et al. 2014) and the ZOI approach, Peters et al. (2018) presented the individual-based mangrove stand model BETTINA_ibm. The aim of this study was to include the effect of the allometric adaptation of trees to different levels of water availability on the selfthinning process and to systematically explore the mechanisms leading to different slopes of the selfthinning line. This was achieved by the mechanistic description of the water uptake of the plants and the subsequent distribution of biomass to the different parts of the tree as described in the section above. A feedback of the vegetation on the salinity is not yet implemented and the abiotic conditions are still assumed to be static and homogeneous in the whole forest plot. Nevertheless, different salinity scenarios led to different average allometries of the trees in the stand and additionally, differing individual neighbourhood interactions had a further impact on the individual tree allometry. On the vegetation side, this approach seems to have the potential to enable the modelling of intra-specific stand properties and opens the way for displaying zonation patterns of different allometric manifestations of trees of the same species. Further, the explicit water use of the single plant in the BETTINA model provides a suitable interface to the water fluxes in the sediment.

None of the models mentioned so far considers an impact of the vegetation on the water availability in time or space, but assumes an infinite subsurface water reservoir. Furthermore, the influence of soil salinity on growth is described unilaterally and non-mechanistically: the salinity of the soil is defined at the stem position of the tree through a predefined value (i.e. as a boundary condition), e.g. through a salinity map. Based on this salinity value, which does not change over time due to tree growth or resource consumption, the tree reduces its growth accordingly. One of the first model examples for the consideration of the influence of water flows on salinity and vegetation can be found in Langevin et al. (2004). This model describes in a mesoscale application the change of a coastal wetland in Florida Bay with a spatial resolution of 300-500 m. This model, however, did not explicitly include the growth of mangrove trees.

Complementary to the models that consider mangrove (as a vegetation type) exclusively, the pioneer model MANHAM (Sternberg et al. 2007; Teh et al. 2008) mimics the sharp boundaries between mangrove stands and freshwater hammocks in coastal ecotones of South Florida. This model includes feedback processes between salinity and plants. It is based on the concept that the water balance in the vadose zone of a vegetation patch is influenced by precipitation, evaporation, transpiration and tidal flux, and that the vadose zone salinity could be changed by freshwater input from rainfall or saline groundwater infiltration due to transpiration. Further, mixing of vadose zone pore water and seawater is dependent on the duration and height of the daily high tide which allows for further topography-related salt intrusion to be included in the model. The vegetation types 'hammock' and 'mangrove' are presented in grid cells and compete for space. Drastically reduced transpiration for the 'hammock' type, when salinities exceeded 5 ppt, describes the dependence of hammocks on freshwater inputs. (Jiang et al. 2012) extended the approach of (Sternberg et al. 2007) further to an individual-based model by adding growth functions and a FON similar to the KiWi-model. In all MANHAM-based models, however, plant water uptake was calculated by species-specific empirical response functions, and the vegetation type is selected between mangrove or freshwater hammocks by a hard switch that is activated when soil porewater exceeds or falls below a fixed salinity threshold. Yet, these approaches highlighted the potential importance of groundwater-vegetation feedbacks to the development of mangroves.

As another development branch from the original MANHAM model, Teh et al. (2013) developed the MANTRA model as a coupling between MANHAM and the process-based saturated-unsaturated subsurface water flow and solute transport model SUTRA (Voss 1984). In this hybrid model, temporal change of 
salinity was coupled with a hydrodynamic model of water overflows due to precipitation and tidal flows, thereby overcoming previous limitations of the simple vadose zone water balance approach of the MANHAM model. (Teh et al. 2015) applied the MANTRA model in storm surge and sea-level rise scenarios in the Everglades to predict successional stages between hammock and mangrove vegetation respectively based on hydrology and salinity dynamics and specific transpiration properties of different plant species.

Furthermore, also based on the MANHAM model, Jiang et al. (2012, 2016) employed a model approach to understand the "switch mechanism" between mangroves and freshwater hammocks. A switch mechanism (as defined by Wilson and Agnew 1992; Agnew et al. 1993) is a process in which a focal community modifies some environmental features by positive feedback effects, which reinforce the development of the focal community. In the model of Jiang et al. (2016), explicit consideration of the groundwater-plant feedbacks led to a stable vegetation mosaic of mangrove and freshwater populations along an environmental gradient. Despite these advancements in understanding groundwater-plant interactions in mangroves, there are a number of shortcomings in the approaches. The representation of the vegetation in the models and the assignment of properties relevant for the impact on the salinity related processes does not yet allow for a detailed prediction of the joined plantsubsurface system and an enhanced understanding of the ecological process in groundwater influenced ecosystems.

Figure 4 summarizes the main strands of existing mangrove models. From FORMAN via KiWi towards BETTINA the representation of single plants improves from a simple gap model with empirical growth functions towards mechanistic resource use and distance-dependent competition approaches. The models based on the MANHAM model focus explicitly on the vegetation-salinity feedback processes. MANTRA includes the sophisticated numerical groundwater approach whereas Jiang et al. (2012) adapts the individual-based FON approach as in the KiWi model.

\section{A brief digression to groundwater modelling}

The focus of this article is to describe the interconnection of mangrove vegetation and water fluxes and

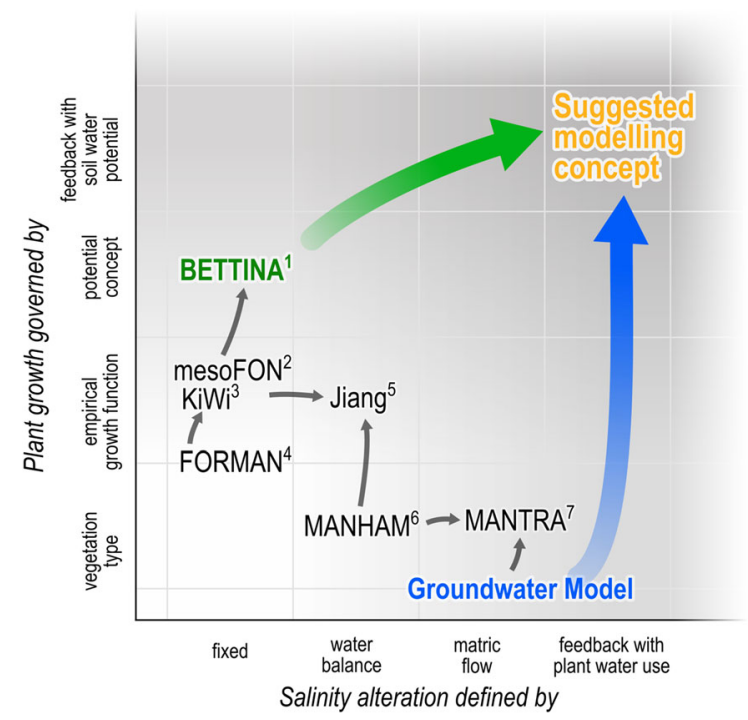

Fig. 4 Existing mangrove single-plant and vegetation stand models, and envisaged coupled approach, (1) Peters et al. (2014), (2) Grueters et al. (2014), (3) Berger and Hildenbrandt (2000), (4) Chen and Twilley (1998), (5) Jiang et al. (2012), (6) Sternberg et al. (2007), (7) Teh et al. (2013)

salinity. It would exceed the framework of this article to analyse the possibilities and requirements of a coupled vegetation-groundwater model to the same extent from the perspective of hydrodynamic groundwater modelling. Nevertheless, we give a short glimpse into specific problems of groundwater models and the potential of an explicit inclusion of vegetation patterns.

Utilizing numerical modelling software has become a common standard to assess groundwater resources (e.g. for sustainable usage), and gain information on their state (e.g. flow direction, confined/ unconfined) and condition (e.g. temperature, dissolved solutes). The major benefit of numerical modelling, in comparison to real-world experiments or observations, lies in the possibility to vary any aspect of the model setup freely and, thus, to investigate a multitude of potential scenarios in a short amount of time. Before using a model for scenario analysis, however, it is necessary to properly describe the system's complexity (i.e. incorporate all relevant system components, e.g. transport processes, subsurface layers, boundary conditions), as well as to determine model parameters in a way that simulation results are similar to observations or measurements. 
Parameters of hydrodynamic groundwater models physically describe the hydraulic properties of the flow matrix and underlie a great spatial heterogeneity. This is in contrast to the majority of existing ecological models, which often describe processes on an empirical, phenomenological level due to missing knowledge about the complex biotic mechanisms. For the coastal zone, however, the process of finding a proper parameter set for a groundwater model can also not be achieved with measurements only (e.g. borehole logs, pumping tests, direct-push-based technology, time-domain electromagnetics, seismographic methods). Instead, model calibration has been done manually, mainly based on the modeller's experience, or with the help of additional calibration tools (e.g. UCODE, Poeter and Hill 1999; PEST, Gallagher and Doherty 2007), which use optimisation theory to find a minimum to a given objective function (e.g. difference between simulated and observed values). Due to the high uncertainty of the subsurface heterogeneity (i.e. parameter distribution), the calibration tools have to deal with an ill-posed problem (i.e. too many degrees of freedom and too few measurement values). The outcome of such a calibration process often leads to a non-unique solution (i.e. multiple realisations with different parameter values, but similar simulation results). To our conviction, a way out of the dilemma can be offered by the incorporation of additional information, which may not directly relate to the classical parameters included in hydrological models. Such information may be derived from surface vegetation and stand properties and incorporated into the model by a dynamic coupling of ecological and groundwater flow models.

As mentioned before, in the case of simulating subsurface flow and solute transport in mangrove forests, there have been few attempts to couple vegetation and groundwater and to represent underground water fluxes and salinity. Langevin et al. (2004) used SEAWAT, a sophisticated continuum groundwater flow and mass transport model, but considered only a large spatial resolution, which is insufficient to understand zonation on stand-based mangrove populations. Jiang et al. (2012) set up the model SEHM, where the subsurface is represented through a conceptual storage model and explicitly state that they are aware of the fact that some "aspects of groundwater dynamics are ignored", but will be taken "into account in future versions of SEHM";
Jiang et al. (2016) continue the development of this model, but not for the subsurface water and solute flux. Teh et al. (2015) compiled the MANTRA model, where SUTRA (a similar continuum model as SEAWAT) is implemented, but show the same limitations as the MANHAM model (being the basis of the ecological model for MANTRA).

\section{Present shortcomings and future challenges}

Status quo and current shortcomings

Modelling plant growth under dynamic environmental conditions, like climate change or sea level rise, or rehabilitation planning of degraded areas, demands a new generation of simulation models that fully consider the various interactions between the organisms and the environment. This includes the following processes: (1) The morphological (and also physiological) adaptation of organisms to the available resources. (2) Changes in the nature and type of interactions between organisms, which are also influenced by resources and their availability. (3) The manifold feedback mechanisms between resource use of organisms and resource availability. The latter is particularly important for mangrove trees since their growth and survival is not only influenced by the water availability, nutrients etc. that they can uptake; they engineer actively their environment including soil properties, hydraulic properties and, subsequently, nutrient, salt and water distribution.

Established mangrove stand models, however, consider below-ground resources only as invariate settings: water and nutrient supply are treated as inexhaustible components that do not show any affect from the plants' resource uptake. Further, resource limitation operates independently from competition. To account for the collective exploitation of common resources, interaction between neighbouring individuals is mainly considered with empirical, phenomenological concepts like FON (Fig. 5, left). Within these concepts, resource distribution is controlled only by plant properties and plants' spatial constellation there is no consideration of the soil properties. Transport and redistribution processes in the subsurface are strongly modulated by hydraulic properties of the soil matrix. For this reason, the area influenced by a tree does not exclusively depend on the size of a tree 


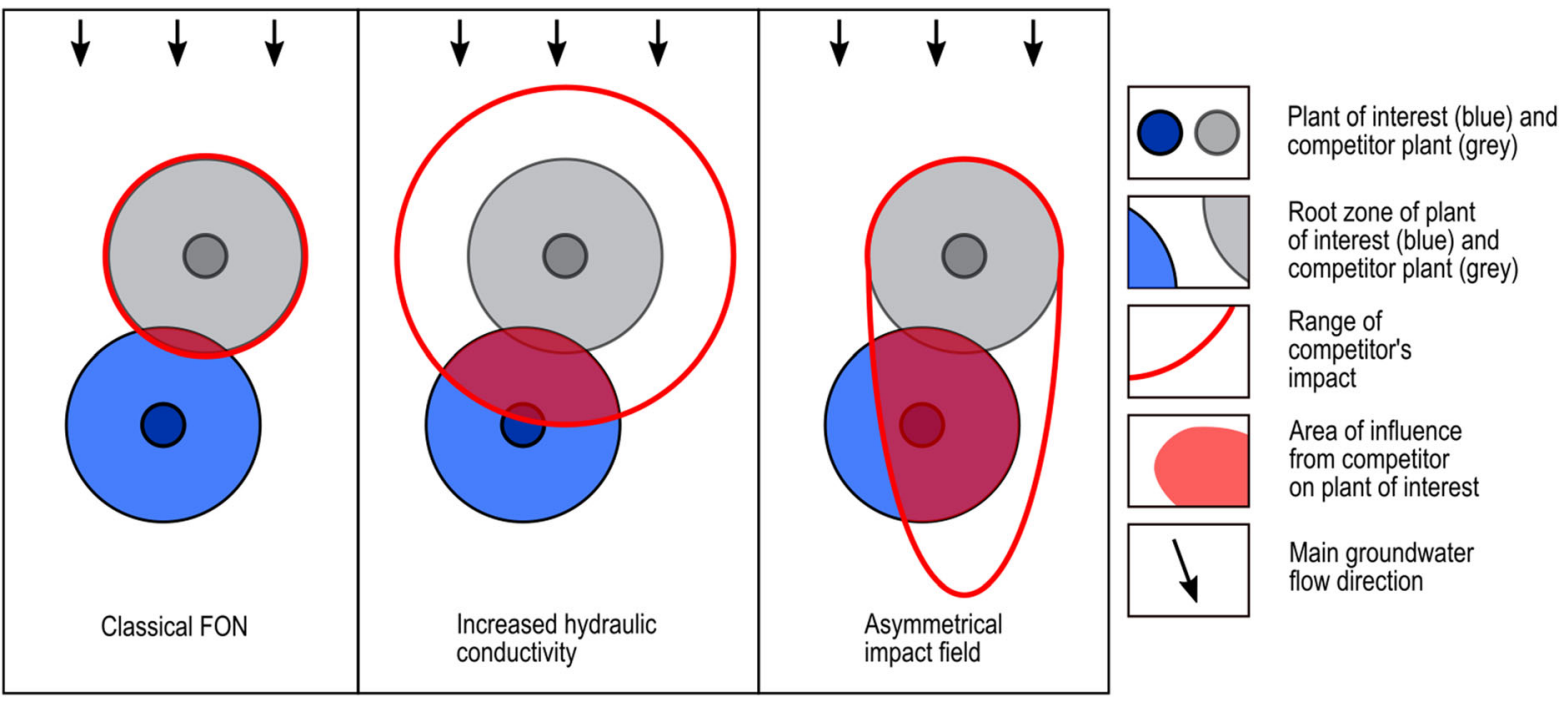

Fig. 5 Left: classical FON-approach with competition area equal to the root zone/tree size; centre: hypothesized bigger field of the impact on competitor plant if considering higher hydraulic

(as assumed by the allometric relation in the ZOI or FON approach), but can vary with soil parameters (Fig. 5, centre). For example, if two equally sized trees (consuming the same amount of water per time) are growing in different soils, e.g. sandy and clayey (i.e. high and low hydraulic conductivity), the impact of the water uptake in the clayey soil will be much stronger in the root zone of the tree but spatially rather restricted to the root zone. In contrast to that, higher hydraulic conductivities in sandy soils lead to a faster spatial levelling and with this, a lower impact in the vicinity but a bigger spatial impact of the focal tree.

On top, anisotropic conditions or spatial gradients lead to anisotropic or asymmetric neighbourhood relations, i.e., the strength of the influence of two trees on each other does not only depend on their size and distance, but very much on their spatial arrangement with respect to hydraulic properties and characteristics (Fig. 5, right).

In addition to that, competition is disconnected from the mass balance of resources. That means that the quantity of present resources remains unaffected by the number and species of competitors at the site. Attempts to overcome that dilemma (like Teh et al. 2008, 2013; Jiang et al. 2012) quantified the plant water use via simple species-specific phenomenologic transpiration approaches to consider the impact of the vegetation type on the salinity. conductivities; right: hypothesized non-circular field if considering groundwater flow directions

Process-based numerical groundwater models, however exist and are capable of describing temporally and spatially explicit density-driven water flow and solute transport in shoreline regions (e.g. Walther et al. 2014). To successfully implement a two-way coupling to describe the dynamics of subsurface systems and the feedback of plant communities on the availability of subsurface resources, we firstly need a single-plant model, which explicitly considers water (and nutrient) uptake to comply with the conservation of mass and which may later be incorporated into a forest stand model. Only this can provide an interface to hydrodynamic groundwater models. To our knowledge, the BETTINA model is the only existing approach to fulfil this condition in terms of water uptake.

The main shortcomings of existing mangrove stand models can be summarised as the following:

1. Water and nutrient budgets are not closed: The most advanced mangrove stand models consider hydrological subsurface processes to describe the feedback of vegetation on salinity. However, they can only roughly quantify the water use of the vegetation by distinguishing different vegetation types. Water uptake on the individual scale is not accounted for. In fact, the tree itself remains excluded from the mass preservation of the water balance. 
2. Compartment coupling is nonexistent: Competition (as well as facilitation) between individuals is a surrogate concept for complex transport and redistribution processes of water and nutrient in the subsurface. Existing concepts to describe competition between neighbours generally neglect below-ground properties and parameters. This has mainly two adverse implications, explained in points 3 and 4 below.

3 . Tree growth and resource availability are independent from surrounding environmental conditions. It is currently not considered that the size of the area impacted by a tree and the strength of the impact on its neighbours depends very much on hydraulic properties of the subsurface. That means, if two equally sized trees (consuming the same amount of water per time) are growing in different soils, e.g. sandy and clayey (i.e. high and low hydraulic conductivity), the impact of the water uptake in the clayey soil will be much stronger in the root zone of the tree but spatially rather restricted to the root zone. In contrast to that, higher hydraulic conductivities in sandy soils lead to a faster spatial levelling and with this, a lower impact in the vicinity but a bigger spatial impact of the focal tree.

4. Temporal and spatial system dynamics are not considered: Anisotropy or spatial gradients are dynamic components, which are specific for a study area and process-dependent, and thus cannot be properly represented by empirical, circular concepts of competition fields.

5. From a groundwater view's perspective, until now, and to the best knowledge of the authors, there is currently no coupled model approach available that considers surface vegetation with individual-based approaches and subsurface fluxes in a continuum model, where it is possible to use surface vegetation information to improve the subsurface parametrisation.

Suggestions for the development of mangrove stand modelling

To tackle the aforementioned limitations and problems, previous efforts of coupling vegetation and groundwater models (Sternberg et al. 2007; Teh et al. 2008, 2015; Jiang et al. 2012, 2016) have to be enhanced and respective models should be developed further. The weakness of these approaches lies still in the representation of the plants: either simple vegetation type or phenomenological approaches hinder a genuine coupling with hydrodynamic models, as a proper interface at the plant models (resource uptake in the form of flow rates) could not be provided. A way out of the dilemma can be found in mechanistic approaches as it is realized in the BETTINA single tree model (Peters et al. 2014): tree growth, allomnormal words in lower case.

Allometry and water uptake on the individual scale are directly controlled by the osmotic potential of the pore water.

Following that tendency, approaches for the individual nutrient use and transport with groundwater should be developed. Due to the preservation of mass and the explicit modelling of water flows, the impact of a plant on its neighbours is an implicit feature of such a model. Phenomenological concepts for competition for water and growth reduction through increased salinity would then become obsolete. Further, the combined vegetation-groundwater model could display developments of the plant-soil-system towards another equilibrium state, when external parameters change. This would significantly increase the predictability under changing environmental conditions and widen the applicability of mangrove stand models. In the more distant future, that may open the way for implementations of soil microbial processes being important for mangrove regeneration at degraded areas (Sherman et al. 1998; Holguin et al. 2001; Bashan and Holguin 2002; Alongi 2005).

Another beneficial side effect of a shift towards more mechanistic descriptions can be a better coalescence between ecological modelling, field science, and experimental approaches. For instance, the main plant parameters in the BETTINA model are minimum plant water potential, xylem conductance and root permeability. There are several experimental studies where such parameters were estimated and their dependence on different environmental conditions has been investigated. Tomlinson (1994) reports a minimum leaf water potential of $-6.5 \mathrm{MPa}$ for Avicennia germinans. Melcher et al. (2001) estimated xylem conductivities for estuarine and coastal stands of Rhizophora mangle or Hao et al. (2009) for dwarf and tall trees of the same species. Field (1984) estimated the water permeability of fine roots of 
Avicennia marina seedlings with two different salinities. Although for now, to our knowledge, complete parameter sets for different mangrove species are not yet available, future experimental studies could directly improve the applicability of the models.

From the viewpoint of groundwater modelling, the coupling of ecological and groundwater models will allow to develop a transferable groundwater calibration concept, which employs data from vegetation zonation or vegetation patterns and allometry as constraints for the characterisation of the subsurface. For example, Li et al. (2009) used spatial patterns of evaporation to deduce the distribution of water potential, and thus aquifer properties. Similar benefits may arise from the inclusion of mangrove stand models as the addition of feedbacks by the vegetation on the subsurface hydraulic properties influence water and solute fluxes and thus the development of the mangrove community (see Fig. 1, "disturbed zonation"), while the plants' activity (water uptake, salt secretion) has influence on the groundwater levels and solute concentration. As a first approach and proof of concept, we consider zonation and allometric manifestation of mangroves as the visible manifestation of the coupled systems, which indicate subsurface hydraulic properties. We therefore hypothesise that information from vegetation zonation patterns and allometric properties of plants can be utilised to infer subsurface properties, which constitutes a challenge in hydrogeological modelling applications.

\section{Outlook}

The two main challenges of ecological modelling today are to provide (1) a more general understanding and theory of how ecological systems work, and (2) testable and robust predictions. To achieve this, structural realism and emergence must become key elements of model design. This is as true for mangrove forest stand models as for models describing other ecological systems.

Mangrove forests, however, have particularly pronounced characteristics due to the adaptation capability of the trees which is unique in comparison to other systems: (i) The forests are exposed to changing soil conditions along the inundation gradient which can result in species zonation patterns pronounced in small spatial scales (a few hundred meters). (ii) Their main entities, the trees, show very high morphological plasticity in response to soil conditions. For this reason, zonation patterns in forest structure can also emerge ranging from tall trees (up to $30-40 \mathrm{~m}$ high under benign conditions) to shrubby trees (sometimes less than $30 \mathrm{~cm}$ high under hypersaline conditions). (iii) Changes in tree morphology (e.g. root to shoot ratio) alter the interactions (ranging from competition to facilitation) between neighbouring plants. (iv) The plants actively change their environment, the surface and subsurface properties, and the related resources. (v) These manifold feedback mechanisms are also influenced by trees morphology and their interactions. For this reasons, individual-based models are best suited for the description of mangrove forests since they describe explicitly the behaviour and variability of organisms, their adaptation, as well as their interactions with their biotic and abiotic environment (DeAngelis and Mooij 2005).

Nevertheless, it is urgently necessary to move from the classical phenomenological view of individualbased models to the next model generation as requested for other systems too (Grimm and Berger 2016; DeAngelis and Yurek 2017). Such models rigorously base the description of the behaviour and interactions of individuals on so-called first principles, which are based on energetic or evolutionary theory and explicitly take into account the linkages of biotic processes with physico-chemical mechanisms (Grimm et al. 2017).

In order to meet these requirements, scientists from different disciplines have to cooperate closely with each other. As we have discussed in this article, for example, it will be essential for the exploration of mangrove forest dynamics to couple groundwater models with vegetation models in a process-oriented way. Only this will allow to mechanistically understand the manifold feedback processes between plants and their local environment. It will help us to realistically predict the effects of environmental changes on the ecological system, and it provides tools to infer hidden subsurface conditions from the visible vegetation structure. That way, not only plant ecology will take advantage from the marriage of both modelling approaches but also ground water research and biogeochemistry.

Furthermore, next generation modelling should aim to develop a general theory to better understand the stability properties of ecological systems and the mechanisms promoting the latter. This is a prerequisite 
and the urgently needed basis for restoring, maintaining and strengthening the resilience of mangrove ecosystems, and supporting sustainable management of natural resources in general. We are aware that this approach has its price in an increasing model complexity and thus data requirements. The first has to be tackled by transparent model description and documentation (see Grimm et al. 2010, 2014; Stillman et al. 2015 among others). The second can be added via local in-situ (e.g. soil water saturation or evaporation through lysimeters or micrometerological methods) or remote sensing monitoring (e.g. land use or vegetation cover through drones or satellites), which will help to transfer the envisaged approach to large spatial scales and applications. Moreover, this allows interdisciplinary research to intensify and scientists from different fields define their corresponding needs more specifically.

Ultimately, next generation modelling should aim to develop a general theory to better understand the stability properties of ecological systems and the mechanisms promoting the latter. This is a prerequisite and the urgently needed basis for restoring, maintaining and strengthening the resilience of mangrove ecosystems, and supporting sustainable management of natural resources in general. Although, our primary focus in this paper is on mangrove-dominated areas and applications, we anticipate that our proposed coupling strategy will have a significant relevance and the potential to be extended to other ecological forest and hydrological sciences.

Acknowledgements Open Access funding provided by Projekt DEAL. This study was financed by the DFG (German Research Foundation) [398759560]. We would like to thank Marie-Christin Wimmler, Alejandra Vovides and Adewole Olagoke for the fruitful discussions about mangrove zonation and flooding regimes. Within the limited timespan of the procession and the review process of this article, Jasper Bathmann contributed considerably to the implementation of the suggested methods. Further, we thank the editors and the reviewer for their support and helpfulness.

Author's contributions The idea, the development of the strategy and the mayor part of the literature study was carried out by RP (mangroves) and MW (groundwater). All of the five authors contributed to the writing of the paper.

Funding This study was financed by the DFG (German Research Foundation) [398759560].

Data Availability Not applicable.

\section{Compliance with ethical standards}

Conflicts of interest The authors declared that they have no conflict of interest.

\section{Code availability Not applicable.}

Open Access This article is licensed under a Creative Commons Attribution 4.0 International License, which permits use, sharing, adaptation, distribution and reproduction in any medium or format, as long as you give appropriate credit to the original author(s) and the source, provide a link to the Creative Commons licence, and indicate if changes were made. The images or other third party material in this article are included in the article's Creative Commons licence, unless indicated otherwise in a credit line to the material. If material is not included in the article's Creative Commons licence and your intended use is not permitted by statutory regulation or exceeds the permitted use, you will need to obtain permission directly from the copyright holder. To view a copy of this licence, visit http://creativecommons.org/licenses/by/4.0/.

\section{References}

Agnew ADQ, Wilson JB, Sykes MT (1993) A vegetation switch as the cause of a forest/mire ecotone in New Zealand. J Veg Sci 4:273-278. https://doi.org/10.2307/3236115

Alongi DM (2005) Mangrove-microbe-soil relations. Interactions Between Macro- and Microorganisms in Marine Sediments. https://doi.org/10.1029/CE060p0085

Ball MC (1988a) Ecophysiology of mangroves. Trees 2:129-142. https://doi.org/10.1007/BF00196018

Ball MC (1988b) Salinity tolerance in the mangroves Aegiceras corniculatum and Avicennia marina. I. Water use in relation to growth, carbon partitioning, and salt balance. Funct Plant Biol 15:447. https://doi.org/10.1071/PP9880447

Ball MC, Pidsley SM (1995) Growth responses to salinity in relation to distribution of two mangrove species, Sonneratia alba and S lanceolata, in Northern Australia. Funct Ecol 9:77. https://doi.org/10.2307/2390093

Bashan Y, Holguin G (2002) Plant growth-promoting bacteria: a potential tool for arid mangrove reforestation. Trees 16:159-166. https://doi.org/10.1007/s00468-001-0152-4

Bathmann J, Peters R, Naumov D, Fischer T, Berger U, Walther M (2020) The MANgrove-GroundwAter feedback model (MANGA) - Describing belowground competition based on first principles. Ecol Model 420:108973. https://doi.org/ 10.1016/j.ecolmodel.2020.108973

Berger U, Hildenbrandt H (2000) A new approach to spatially explicit modelling of forest dynamics: spacing, ageing and neighbourhood competition of mangrove trees. Ecol Model 132:287-302. https://doi.org/10.1016/S0304-3800(00) 00298-2

Berger U, Adams M, Grimm V, Hildenbrandt H (2006) Modelling secondary succession of neotropical mangroves: Causes and consequences of growth reduction in pioneer species. Perspect Plant Ecol 7:243-252. https://doi.org/10. 1016/j.ppees.2005.08.001 
Berger U, Hildenbrandt H, Grimm V (2008a) Towards a standard for the individual-based modeling of plant populations: Self-thinning and the field-of-neighborhood approach. Nat Resour Model 15:39-54. https://doi.org/10. 1111/j.1939-7445.2002.tb00079.x

Berger U, Piou C, Schiffers K, Grimm V (2008b) Competition among plants: Concepts, individual-based modelling approaches, and a proposal for a future research strategy. Perspect Plant Ecol 9:121-135. https://doi.org/10.1016/j. ppees.2007.11.002

Berger U, Rivera-Monroy VH, Doyle TW, Dahdouh-Guebas F, Duke NC, Fontalvo-Herazo ML, Hildenbrandt H, Koedam N, Olag Mehlig U, Piou C, Twilley RR (2008c) Advances and limitations of individual-based models to analyze and predict dynamics of mangrove forests: A review. Aquat Bot 89:260-274. https://doi.org/10.1016/j.aquabot.2007. 12.015

Bhat NR, Suleiman MK, Shahid SA (2004) Mangrove, Avicennia marina, establishment and growth under the arid climate of Kuwait. Arid Land Res Manag 18:127-139. https://doi.org/10.1080/15324980490280799

Botkin DB, Janak JF, Wallis JR (1972) Some ecological consequences of a computer model of forest growth. J Ecol 60:849-872. https://doi.org/10.2307/2258570

Breckling B, Müller F, Reuter H, Hölker F, Fränzle O (2005) Emergent properties in individual-based ecological models - introducing case studies in an ecosystem research context. Ecol Model 186:376-388. https://doi.org/10.1016/j. ecolmodel.2005.02.008

Chave J, Andalo C, Brown S, Cairns MA, Chambers JQ, Eamus D, Fölster H, Fromard F, Higuchi N, Kira T, Lescure J-P, Nelson BW, Ogawa H, Puig H, Riéra B, Yamakura T (2005) Tree allometry and improved estimation of carbon stocks and balance in tropical forests. Oecologia 145:87-99. https://doi.org/10.1007/s00442-005-0100-x

Chen R, Twilley RR (1998) A gap dynamic model of mangrove forest development along gradients of soil salinity and nutrient resources. J Ecol 86:37-51

Crase B, Liedloff A, Vesk PA, Burgman MA, Wintle BA (2013) Hydroperiod is the main driver of the spatial pattern of dominance in mangrove communities. Global Ecol Biogeogr 22(7):806-817. https://doi.org/10.1111/geb.12063

Czárán T (1998) Spatiotemporal models of population and community dynamics. Springer Science \& Business Media

da SternbergSL L, Teh SY, Ewe SML, Miralles-Wilhelm F, DeAngelis DL (2007) Competition between hardwood hammocks and mangroves. Ecosystems 10:648-660. https://doi.org/10.1007/s10021-007-9050-y

DeAngelis DL, Mooij WM (2005) Individual-based modeling of ecological and evolutionary processes. Annu Rev Ecol Evol S 36:147-168. https://doi.org/10.1146/annurev. ecolsys.36.102003.152644

DeAngelis DL, Yurek S (2017) Spatially explicit modeling in ecology: a review. Ecosystems 20:284-300. https://doi. org/10.1007/s10021-016-0066-Z

Doyle TW, Girod GF, Books MA (2003) Modeling mangrove forest migration along the southwest coast of Florida under climate change. Integrated assessment of the climate change impacts on the gulf coast region. Louisiana State University Graphic Services, Gulf Coast Climate Change Assessment Council (GCRCC), pp 211-222
Duke NC, Ball MC, Ellison JC (1998) Factors influencing biodiversity and distributional gradients in mangroves. Glob Ecol Biogeogr 7:27. https://doi.org/10.2307/2997695

Ellison AM (2000) Mangrove restoration: Do we know enough? Restor Ecol 8:219-229. https://doi.org/10.1046/j.1526100x.2000.80033.x

Ellison AM, Mukherjee BB, Karim A (2000) Testing patterns of zonation in mangroves: scale dependence and environmental correlates in the Sundarbans of Bangladesh. J Ecol 88:813-824. https://doi.org/10.1046/j.1365-2745.2000. 00500.x

Feller IC, Whigham DF, McKee KL, Lovelock CE (2003) Nitrogen limitation of growth and nutrient dynamics in a disturbed mangrove forest, Indian River Lagoon, Florida. Oecologia 134:405-414. https://doi.org/10.1007/s00442002-1117-z

Field CD (1984) Movement of ions and water into the xylem sap of tropical mangroves In: Teas HJ (ed) Physiology and management of mangroves. Tasks for vegetation science, vol 9. Springer, Dordrecht, https://doi.org/10.1007/978-94009-6572-0_6

Gallagher M, Doherty J (2007) Parameter estimation and uncertainty analysis for a watershed model. Environ Modell Softw 22:1000-1020. https://doi.org/10.1016/j. envsoft.2006.06.007

Grace J (ed) (2012) Perspectives on plant competition. Elsevier

Grimm V, Berger U (2016) Structural realism, emergence, and predictions in next-generation ecological modelling: Synthesis from a special issue. Ecol Model 326:177-187. https://doi.org/10.1016/j.ecolmodel.2016.01.001

Grimm V, Berger U, DeAngelis DL, Polhill JG, Giske J, Railsback SF (2010) The ODD protocol: a review and first update. Ecol Model 221:2760-2768. https://doi.org/10. 1016/j.ecolmodel.2010.08.019

Grimm V, Augusiak J, Focks A, Frank BM, Gabsi F, Johnston ASA, Liu C, Martin BT, Meli M, Radchuk V, Thorbek P, Railsback SF (2014) Towards better modelling and decision support: Documenting model development, testing, and analysis using TRACE. Ecol Model 280:129-139. https://doi.org/10.1016/j.ecolmodel.2014.01.018

Grimm V, Ayllón D, Railsback SF (2017) Next-generation individual-based models integrate biodiversity and ecosystems: yes we can, and yes we must. Ecosystems 20:229-236. https://doi.org/10.1007/s10021-016-0071-2

Grueters U, Seltmann T, Schmidt H, Horn H, Pranchai A, Vovides AG, Peters R, Vogt J, Dahdouh-Guebas F, Berger U (2014) The mangrove forest dynamics model mesoFON. Ecol Model 291:28-41. https://doi.org/10.1016/j. ecolmodel.2014.07.014

Hao G-Y, Jones TJ, Luton C, Zhang Y-J, Manzane E, Scholz FG, Bucci SJ, Cao K-F, Goldstein G (2009) Hydraulic redistribution in dwarf Rhizophora mangle trees driven by interstitial soil water salinity gradients: impacts on hydraulic architecture and gas exchange. Tree Physiol 29:697-705. https://doi.org/10.1093/treephys/tpp005

Hazra S, Ghosh T, Dasgupta R, Sen G (2002) Sea level and associated changes in the Sundarbans. Sci Cult 68:309-321

Holguin G, Vazquez P, Bashan Y (2001) The role of sediment microorganisms in the productivity, conservation, and rehabilitation of mangrove ecosystems: an overview. Biol 
Fert Soils 33:265-278. https://doi.org/10.1007/ s003740000319

Jiang J, DeAngelis DL, Smith TJ, Teh SY, Koh H-L (2012) Spatial pattern formation of coastal vegetation in response to external gradients and positive feedbacks affecting soil porewater salinity: a model study. Landscape Ecol 27:109-119. https://doi.org/10.1007/s10980-011-9689-9

Jiang J, DeAngelis DL, Teh S-Y, Krauss KW, Wang H, Li H, Smith TJ, Koh H-L (2016) Defining the next generation modeling of coastal ecotone dynamics in response to global change. Ecol Model 326:168-176. https://doi.org/10.1016/ j.ecolmodel.2015.04.013

Komiyama A, Poungparn S, Kato S (2005) Common allometric equations for estimating the tree weight of mangroves. J Trop Ecol 21:471-477. https://doi.org/10.1017/ S0266467405002476

Komiyama A, Ong JE, Poungparn S (2008) Allometry, biomass, and productivity of mangrove forests: A review. Aquat Bot 89:128-137. https://doi.org/10.1016/j.aquabot.2007.12. 006

Langevin CD, Swain ED, Wang JD, Wolfert MA, Schaffranek RW, Riscassi AL, Bay F (2004) Development of coastal flow and transport models in support of Everglades restoration. US Geological Survey Fact Sheet 3130:3-6

Lewis RR, Milbrandt EC, Brown B, Krauss KW, Rovai AS, Beever JW, Flynn LL (2016) Stress in mangrove forests: Early detection and preemptive rehabilitation are essential for future successful worldwide mangrove forest management. Mar Pollut Bull 109:764-771. https://doi.org/10. 1016/j.marpolbul.2016.03.006

Li HT, Brunner P, Kinzelbach W, Li WP, Dong XG (2009) Calibration of a groundwater model using pattern information from remote sensing data. J Hydrol 377:120-130. https://doi.org/10.1016/j.jhydrol.2009.08.012

Lovelock CE, Cahoon DR, Friess DA, Guntenspergen GR, Krauss KW, Reef R, Rogers K, Saunders ML, Sidik F, Swales A, Saintilan N, Thuyen LX, Triet T (2015) The vulnerability of Indo-Pacific mangrove forests to sea-level rise. Nature 526:559-563. https://doi.org/10.1038/ nature 15538

Lovelock CE, Reef R, Ball MC (2017) Isotopic signatures of stem water reveal differences in water sources accessed by mangrove tree species. Hydrobiologia 803:133-145. https://doi.org/10.1007/s10750-017-3149-8

Matthijs S, Tack J, van Speybroeck D, Koedam N (1999) Mangrove species zonation and soil redox state, sulphide concentration and salinity in Gazi Bay (Kenya), a preliminary study. Mangroves and Salt Marshes 3:243-249. https://doi.org/10.1023/A:1009971023277

McKee KL (1993) Soil Physicochemical Patterns and Mangrove Species Distribution-Reciprocal Effects? J Ecol 81:477. https://doi.org/10.2307/2261526

Melcher PJ, Goldstein G, Meinzer FC, Yount DE, Jones TJ, Holbrook NM, Huang CX (2001) Water relations of coastal and estuarine Rhizophora mangle: xylem pressure potential and dynamics of embolism formation and repair. Oecologia 126:182-192. https://doi.org/10.1007/s004420000519

Michailoff I (1943) Zahlenmäßiges Verfahren für die Ausführung der Bestandeshöhenkurven. Cbl und Thar Forstl Jahrb 6:273-279
Olagoke A (2016) Towards a better characterization of morphological plasticity and biomass partitioning of trees in structual dynamics of mangrove forests. Dissertation, TU Dresden

Pacala SW, Silander JA (1985) Neighborhood models of plant population dynamics. I. Single-species models of annuals Am Nat 125:385-411

Peters R, Vovides AG, Luna S, Grüters U, Berger U (2014) Changes in allometric relations of mangrove trees due to resource availability-A new mechanistic modelling approach. Ecol Model 283:53-61. https://doi.org/10.1016/ j.ecolmodel.2014.04.001

Peters R, Olagoke A, Berger U (2018) A new mechanistic theory of self-thinning: Adaptive behaviour of plants explains the shape and slope of self-thinning trajectories. Ecol Model 390:1-9. https://doi.org/10.1016/j.ecolmodel.2018.10.005

Poeter EP, Hill MC (1999) UCODE, a computer code for universal inverse modeling. Comput Geosci 25:457-462. https://doi.org/10.1016/S0098-3004(98)00149-6

Polidoro BA, Carpenter KE, Collins L, Duke NC, Ellison AM, Ellison JC, Farnsworth EJ, Fernando ES, Kathiresan K, Koedam NE, Livingstone SR, Miyagi T, Moore GE, Ngoc Nam V, Ong JE, Primavera JH, Salmo SG, Sanciangco JC, Sukardjo S, Wang Y, Yong JWH (2010) The loss of species: Mangrove extinction risk and geographic areas of global concern. PLoS ONE 5:e10095. https://doi.org/10. 1371/journal.pone.0010095

Pretzsch H (2010) Forest dynamics, growth and yield. Springer, Berlin Heidelberg, Berlin, Heidelberg. https://doi.org/10. 1007/978-3-540-88307-4

Rabinowitz D (1978) Dispersal properties of mangrove propagules. Biotropica 10:47. https://doi.org/10.2307/ 2388105

Reuter H, Hölker F, Middelhoff U, Jopp F, Eschenbach C, Breckling B (2005) The concepts of emergent and collective properties in individual-based models - Summary and outlook of the Bornhöved case studies. Ecol Model 186:489-501. https://doi.org/10.1016/j.ecolmodel.2005. 02.014

Runting RK, Lovelock CE, Beyer HL, Rhodes JR (2017) Costs and opportunities for preserving coastal wetlands under sea level rise. Conserv Lett 10:49-57. https://doi.org/10.1111/ conl.12239

Saintilan N (1997) Above- and below-ground biomass of mangroves in a sub-tropical estuary. Mar Freshwater Res 48:601. https://doi.org/10.1071/MF97009

Schwinning S, Weiner J (1998) Mechanisms determining the degree of size-asymmetry in competition among plants. Oecologia 113:447-455

Semeniuk V (1983) Mangrove distribution in Northwestern Australia in relationship to regional and local freshwater seepage. Vegetatio 53:11-31

Sherman RE, Fahey TJ, Howarth RW (1998) Soil-plant interactions in a neotropical mangrove forest: iron, phosphorus and sulfur dynamics. Oecologia 115:553-563. https://doi. org/10.1007/s004420050553

Shimano K (1997) Analysis of the relationship between DBH and crown projection area using a new model. J For Res 2:237-242. https://doi.org/10.1007/BF02348322 
Smith TJ (1987) Seed predation in relation to tree dominance and distribution in mangrove forests. Ecology 68:266-273. https://doi.org/10.2307/1939257

Stillman RA, Railsback SF, Giske J, Berger U, Grimm V (2015) Making predictions in a changing world: The benefits of individual-based ecology. Bioscience 65:140-150. https:// doi.org/10.1093/biosci/biu192

Swales A, Reeve G, Cahoon DR, Lovelock CE (2019) Landscape evolution of a fluvial sediment-rich Avicennia marina mangrove forest: insights from seasonal and interannual surface-elevation dynamics. Ecosystems. https:// doi.org/10.1007/s10021-018-0330-5

Teh SY, DeAngelis DL, da Silveira Lobo Sternberg L, MirallesWilhelm FR, Smith TJ, Koh HL (2008) A simulation model for projecting changes in salinity concentrations and species dominance in the coastal margin habitats of the Everglades. Ecol Model. https://doi.org/10.1016/j. ecolmodel.2007.12.007

Teh SY, Koh HL, DeAngelis DL, Turtora M (2013) Interaction between salinity intrusion and vegetation succession: a modeling approach. Theor Appl 3:032001. https://doi.org/ $10.1063 / 2.1303201$

Teh SY, Turtora M, DeAngelis D, Jiang J, Pearlstine L, Smith T, Koh H (2015) Application of a coupled vegetation competition and groundwater simulation model to study effects of sea level rise and storm surges on coastal vegetation. J Mar Sci Eng 3:1149-1177. https://doi.org/10.3390/ jmse3041149

Thom BG (1967) Mangrove ecology and deltaic geomorphology: Tabasco. Mexico J Ecol 55:301. https://doi.org/10. 2307/2257879

Tietjen B, Jeltsch F, Zehe E, Classen N, Groengroeft A, Schiffers K, Oldeland J (2009) Effects of climate change on the coupled dynamics of water and vegetation in drylands. Ecohydrology 3:226-237. https://doi.org/10.1002/eco.70

Tomlinson PB (1994) The botany of mangroves. Cambridge University Press, Cambridge Tropical Biology Series

Traill LW, Perhans K, Lovelock CE, Prohaska A, McFallan S, Rhodes JR, Wilson KA (2011) Managing for change: wetland transitions under sea-level rise and outcomes for threatened species. Divers Distrib 17:1225-1233. https:// doi.org/10.1111/j.1472-4642.2011.00807.x

Twilley RR, Rivera-Monroy VH, Chen R, Botero L (1999) Adapting an ecological mangrove model to simulate trajectories in restoration ecology. Mar Pollut Bull 37:404-419. https://doi.org/10.1016/S0025-326X(99) 00137-X

Vogt J, Piou C, Berger U (2014) Comparing the influence of large- and small-scale disturbances on forest heterogeneity: A simulation study for mangroves. Ecol Complex 20:107-115. https://doi.org/10.1016/j.ecocom.2014.09. 008

Voss C (1984) A finite-element simulation model for saturatedunsaturated, fluid-density-dependent groundwater flowFig with energy transport or chemically-reactive single-species solute transport. Water Resources Investigation Report 84:4369

Vovides AG, Vogt J, Kollert A, Berger U, Grueters U, Peters R, Lara-Domínguez AL, López-Portillo J (2014) Morphological plasticity in mangrove trees: salinity-related changes in the allometry of Avicennia germinans. Trees 28:1413-1425. https://doi.org/10.1007/s00468-014-10448

Walther M, Bilke L, Delfs J-O, Graf T, Grundmann J, Kolditz O, Liedl R (2014) Assessing the saltwater remediation potential of a three-dimensional, heterogeneous, coastal aquifer system. Environ Earth Sci 72:3827-3837. https:// doi.org/10.1007/s12665-014-3253-2

Watson JG (1928) Mangrove forests of the Malay Peninsula. Malayan Forest Records 6

Weiner J, Stoll P, Muller-Landau H, Jasentuliyana A (2001) The effects of density, spatial pattern, and competitive symmetry on size variation in simulated plant populations. Am Nat 158:438-450. https://doi.org/10.1086/321988

Wilson JB, Agnew ADQ (1992) Positive-feedback switches in plant communities. In: Advances in Ecological Research. Academic Press, pp 263-336. https://doi.org/10.1016/ S0065-2504(08)60149-X

Wu H-I, Sharpe PJH, Walker J, Penridge LK (1985) Ecological field theory: A spatial analysis of resource interference among plants. Ecol Model 29:215-243. https://doi.org/10. 1016/0304-3800(85)90054-7

Publisher's Note Springer Nature remains neutral with regard to jurisdictional claims in published maps and institutional affiliations. 